

\section{Ciencia y literatura en diálogo con la ciudad}

Inaê Elias Magno da Silva

Dirección: SHCGN 708, Bloco H, apto. 403, BrasíliaDF-Brasil, 70740-768

Teléfono: 5561 3274-3836

5561 9218-4212

Fax: 5561 3215-9716

Correo eletrónico: inae.magno@uol.com.br

inae.silva@camara.gov.br

Afiliación institucional: Cámara de los Diputados de

Brasil

* Doctora en Sociología por la Universidade de Brasilia - UnB y consultora en la Cámara de los

Diputados de Brasil (inae.magno@uol.com.br).

Tânia Elias Magno da Silva

Dirección: Rua Leonel Curvelo, 320, Salgado Filho, Aracaju-SE-Brasil, 49050-480

Teléfono: 5579 3211-8078

Fax:

Correo eletrónico: taniamagno@uol.com.br Afiliación institucional: Universidade Federal de Sergipe (Universidad de Sergipe)

${ }^{* *}$ Doctora en Antropología por la Pontifícia Universidade Católica de São Paulo - PUCSP y profesora del Núcleo de Postgrado en Ciencias Sociales de la Universidade Federal de Sergipe - UFS (taniamagno@uol.com.br).

Adriana Maria Giubertti Dirección: SHCGN 708, Bloco H, apto. 403, BrasíliaDF-Brasil, 70740-768

Teléfono: 5561 3222-2127 $55619155-2660$

Fax: 5561 3215-9716

Correo eletrónico: adrianagiubertti@yahoo.com.br Afiliación institucional: Ministerio del Trabajo y

Empleo de Brasil Historiadora y Doctora en Sociología por la Universidade de Brasilia - UnB y coordinadora del Observatorio del Trabajo de Brasil y del MERCOSUL en el Ministerio del Trabajo y Empleo de Brasil 


\section{Introducción}

Nuestra propuesta, en este texto, es la de discutir la ciudad y el urbano ${ }^{1}$ como objetos complejos de la investigación científica, los cuales piden no solamente una mirada interdisciplinaria para su mejor comprensión como también el diálogo de las diversas disciplinas científicas que se dedican a su estudio juntamente con el arte y otras formas del libre pensar. La Literatura es presentada por nosotras como una fuente amplia y muy valiosa no solamente de datos y discurso, pero también de inspiración creativa para el campo de estudio del urbano y de la ciudad.

No nos fijaremos en una ciudad, en un autor o en un tiempo histórico específicos. Nuestra intención es justo proponer que se comprenda el pensamiento literario como una modalidad del libre pensar también libre en el tiempo y en el espacio, pero, así mismo - o justamente por eso -, valida para las reflexiones sobre la ciudad y el urbano con base en esos dos ejes. Por esa libertad, el artista puede hablar de ciudades reales o ficticias, de tiempos históricos vividos o inventados, sin atarse al compromiso con aquellas que, según Trujillo, son las características del pensamiento científico tradicional - las cuales, para nosotras, son funcionales para profundizar el conocimiento disciplinario, pero crean limitaciones al propio pensar de la ciencia de modo más amplio:

El conocimiento científico es real (factual) porque maneja con ocurrencias o hechos [...]. Constituye un conocimiento “contingente”, pues sus proposiciones o hipótesis tienen su veracidad o falsedad conocida por medio de la experiencia e no solamente por la razón, como ocurre con el pensamiento filosófico. Es sistemático, ya que se trata de un

1 Utilizaremos la palabra "urbano" en sentido prioritariamente sustantivo. Por "urbano" tomamos, en el presente texto, no solamente aquello que adjetiva la ciudad, en especial lo que la contextualiza materialmente, pero también - o más importante quizá - suya dimensión inmaterial, o sea, aquello que la caracteriza como hecho social. Por eso no hablaremos de "contexto urbano" pero si de "urbano" solamente. 
saber ordenado lógicamente, formando un sistema de ideas (teoría) y no conocimientos dispersos o inconexos. Posee la característica de someterse a la verificación, a tal punto que las afirmaciones (hipótesis) que no pueden ser comprobadas no pertenecen al ámbito de la ciencia. Constituyese en conocimiento falible, en virtud de no ser definitivo, absoluto o final y, por este motivo, es aproximadamente exacto: nuevas proposiciones y el desarrollo de técnicas pueden reformular el acervo de teorías existente².

Al artista se le autoriza sobretodo la libertad, sea del devaneo, de la imaginación, de la interpretación de las situaciones observadas o vividas, de la estilística y otras. A esa libertad corresponde una mayor sensibilidad del pensamiento literario para la percepción de los hechos cotidianos y de los cambios sociales y materiales de la vida humana. La socióloga Barbara Freitag $^{3}$, incluso, afirma que el arte, en especifico la Literatura, tiene el papel de sismógrafo de las nuevas formas de sociabilidad. Un papel, vale decir, que tiene alerta a filósofos, sociólogos, cientistas políticos, economistas y demógrafos, los cuales solo a posteriori, o sea, después de alertados por los profesionales de la creatividad, buscan conceptualizar y explicar.

Como dice el crítico literario Antonio Candido, "el recado del escritor se construye a partir del mundo, pero crea un mundo nuevo, cuyas leyes hacen sentir mejor la realidad originaria"4. La coherencia es el centro metodológico en el cual se sostiene el sentimiento de vida o realidad que el texto literario transmite, sea el del tipo realista o no. Suya verosimilitud, luego, se fundamenta más en el encadenamiento narrativo que en los hechos reales que describe o de los cuales

$2 C f$. Eva Maria Lakatos y Marina de Andrade Marconi, Metodología científica (São Paulo, Brasil: Atlas, 1982), 20 - traducción nuestra.

$3 C f$. Barbara Freitag, Cidade dos homens (Rio de Janeiro, Brasil: Tempo Brasileiro, 2002).

4 Cf. Antonio Candido, O discurso e a cidade (São Paulo, Brasil: Duas Cidades, 1993), 10 - traducción nuestra. 
apropiase para crear suyas realidades imaginarias.

Sin embargo, para muchos cientistas, es justamente por esa libertad creativa y eso método de "invención" del real con base en la estructura narrativa, que el pensamiento literario no sirve como fuente de datos o canal de diálogo con la ciencia. Ejemplo de eso, es que ello siquiera es reconocido como un tipo de conocimiento específico por algunos de los estudiosos clásicos de la Metodología de las ciencias 5 .

Nuestra intención, en este breve paper, es cuestionar la validez metodológica de eso rechazo para los objetivos de investigación de las disciplinas que estudian el urbano. Nuestra cuestión central es: ¿Sirve la Literatura a los estudios científicos del urbano? Para responderla, hacemos uso de la contribución del pensamiento complejo a la crítica de la ciencia positivista y proponemos el debate en rededor no de una o otra disciplina científica dedicada al estudio de la cuidad, pero a un conjunto interdisciplinario que estudia el urbano.

Nosotras entendemos que el urbano, como manifestación social de la vida de las ciudades, extrapola a la grande ciudad - su ícono -, sea ella la metrópoli moderna o la megalópolis postmoderna ${ }^{6}$, y se manifiesta también como racionalidad o hábitus $^{7}$ en otros tipos de asentamientos humanos. Ejemplo de eso son las villas, las aldeas, los pueblos, i paesi (caso italiano) y quizá el propio campo, pues en el mundo actual los canales de comunicación a partir de la ciudad se encuentran permanentemente abiertos, construyendo la fuerza simbólica del urbano para allá de los limites espaciales de la propia cuidad.

Aunque nuestro debate sea más teórico, creemos que nuestros cuestionamientos puedan

5 Para Trujillo apud Lakatos y Marconi, el conocimiento se divide en cuatro tipos: conocimiento popular; conocimiento filosófico; conocimiento religioso; y conocimiento científico. El arte, y junto, la Literatura, no es apuntada como conocimiento. $C f$. Lakatos y Marconi.

$6 \quad C f$. Bárbara Freitag, Teorias da cidade (Campinas, Brasil: Papirus Editora, 2006).

$7 \quad C f$. Pierre Bourdieu, O poder simbólico (Lisboa, Portugal: Difel, 1989). 
servir para que los encuestadores centroamericanos de la ciudad y del urbano, sea en la perspectiva histórica o otras, puedan pensar suyas distintas realidades particulares dialogando con otras formas de saber que no la ciencia clásica.

\section{Ciudad, interdisciplinaridad y Literatura}

En el libro Teorias da cidade ("Teorías de la ciudad"), la socióloga Barbara Freitag intenta reunir aquellas que, según ella, serían las escuelas más importantes para la construcción teórica de la ciudad. Su esfuerzo de sistematización resultó en la reunión de los más expresivos teóricos de la ciudad en cuatro escuelas nacionales de estudio: la Escuela Alemana, donde se encuentran Max Weber, George Simmel, Walter Benjamin y Ronald Daus; la Escuela Francesa, con destaque para Charles Fourieur, Georges Haussmann, Le Corbusier, Claude Lévi-Strauss, Alain Touraine, Henri Lefebvre y Manuel Castells; la Escuela Anglo-saxónica del Reino Unido, donde figuran Thomas Morus, Ebenezer Howard, Patrick Geddes, Raymnod Unwin y Peter Hall; y por fin, la Escuela Anglo-saxónica Americana, con la presencia de la Escuela de Chicago y sus autores, Lewis Mumford, Richard Sennet y Saskia Sassen.

Además del esfuerzo de sistematización de pensamientos y campos del saber tan distintos - que pasan por la Sociología, la Arquitectura y el Urbanismo, la Historia, la Antropología, el Planeamiento Urbano y otros -, la obra de Freitag presenta al menos dos puntos de grande relevancia para las reflexiones que proponemos en este texto: la importancia-o, más, la necesidad - de la interdisciplinaridad en los estudios de la ciudad, y las diferentes dimensiones del urbano escogidas por los autores como punto de partida para sus estudios y analices.

$8 \quad C f$. Freitag, "Teorias da cidade". 
Respecto del primer punto, así pronunciase la autora:

Vale resaltar que el interés en la cuestión de las ciudades es - y necesita ser interdisciplinario, abarcando varios registros de la realidad, como el urbano, el económico, el político, el social y el cultural. Así, una teoría de las ciudades tiene que ser obligatoriamente interdisciplinaria. [...] no podemos hablar de una "teoría de las ciudades", o sea, una teoría que valga para todas las ciudades que encontramos a través de la historia y en las más variadas regiones. Debemos, sí, hablar de teorías de la ciudad, o sea, de las varias tentativas de tratamiento conceptual de la ciudad como un fenómeno universal de la vida en sociedad ${ }^{9}$.

La dificultad presentada por Freitag para el tratamiento unificado de la ciudad encontrase, además de otras, creemos, en esa que es una de sus más importantes particularidades: el hecho de ella ser todo y parte al mismo tiempo. Silva ${ }^{10}$ sugiere el reconocimiento de un tipo propio de totalidad de la ciudad, al cual llama totalidad compleja. La autora propone que los estudiosos de la ciudad en los distintos campos del conocimiento la reconozcan como un objeto de estudio complejo que presenta, por consiguiente, el tipo de totalidad plural que caracteriza los objetos complejos. En palabras de la autora:

El reconocimiento de la totalidad compleja de la ciudad presupone, por parte de la ciencia y del propio cientista, el desarrollo de una capacidad perceptiva múltipla, que ultrapase las limitaciones de la visión y, por consiguiente, de la simple observación, que sea capaz de reconocer el objeto para delante de sus aspectos inmediatamente presentados, en general, $9 \quad C f$. Freitag, "Teorias da cidade", 11-12 - traducción nuestra.

10 Inaê Elias Magno da Silva, "Pensamento complexo: alternativa para o resgate intelectual da totalidade urbana", Revista Brasileira de Sociologia das Emoções (Brasil), 5, 14/15 (2006) traducción nuestra. 
su materialidad, incorporando el no aprensible, porque no manipulable, al campo de dominio de la ciencia y no solamente de los pensamientos filosófico y mítico ${ }^{11}$.

La sugerencia de reconocimiento de la totalidad compleja de la ciudad implica en otro reconocimiento: el de que la ciudad no se reduce a la condición de todo o parte "porque su constitución compleja es justamente el resultado de la mutua existencia de ambas las condiciones: ella es un todo en partes y la parte de un todo"12. En otras palabras, es decir que "toda ciudad existente es, por un lado, un cosmos [...] y, por otro lado, cada ciudad situase en el cuerpo de un universo social más amplio y múltiplo del cual ella es solamente un fragmento"13.

La admisión de la relación cosmos/fragmento como propia al fenómeno urbano resulta en una dupla conclusión lógica: en primer lugar, por ser imposible repetir la combinación espacio-sociedad que conforma históricamente cada ciudad empírica, concluyese que no existen dos ciudades iguales en el mundo [o mismo en el tiempo]; de otra parte, por no existir ciudad que no contenga aspectos esenciales del universo social al cual ella constituye, concluyese que, en los limites de una misma civilización o de una misma sociedad, no existe ciudad completamente extraordinaria en relación a las demás ${ }^{14}$.

Esa doble conclusión lógica nos lleva al segundo aspecto presentado por Freitag: los diferentes puntos de partida elegidos por los estudiosos de la ciudad, que resultan evidentemente en puntos de llegada también distintos.

Si cada ciudad es igualmente única pero semejante a otras, las miradas intelectuales sobre ellas se pueden producir básicamente de dos maneras: o el examen recae sobre una ciudad 11 Ibid., 171 - traducción nuestra.

12 Ibid., 176 - traducción nuestra.

$13 \quad$ Ibid.

14 Ibid., 177 - traducción nuestra. 
empírica cualquiera (San Paulo, Paris, Bogotá, Chicago, San José y otras), o ello recae sobre tipologías o teorías de la ciudad pensada de modo más general. Es evidente la existencia de diálogo entre esos dos puntos de partida, pero mucho más del primero con el segundo que el inverso.

El enfoque disciplinario tiene mucha relevancia en la elección del punto de partida de las analices. Mientras los historiadores tienen el tiempo como categoría fundamental de análisis de la ciudad, los geógrafos y urbanistas parten del espacio para estudiar el mismo fenómeno. Ya los sociólogos y antropólogos parten de las dimensiones sociales y culturales del urbano, mientras los cientistas políticos tienen su foco en las relaciones de poder. El único que puede partir donde quiera - el espacio edificado, el psicológico social o individual del citadino, el tiempo, las relaciones sociales o políticas, las manifestaciones culturales y tantos otros aspectos del urbano - y aunque hacer dialogar harmoniosamente cada un de los dominios seleccionados, es el artista. Eso por ser libre la manifestación de su pensar: libre tanto de los rigores de la alta racionalidad cuanto de los esfuerzos de legitimación disciplinaria, ambos típicos de la ciencia tradicional.

Puntos de partida distintos suponen puntos de llegada igualmente distintos. Así es que mientras los arquitectos racionalistas, porque parten del espacio, miran cuatro funciones básicas y permanentes en la ciudad - el habitar, el trabajar, el circular y el divertirse ${ }^{15}$-, los historiadores, que parten del tiempo, entienden que las funciones que se identifican en la ciudad no son funciones abstractas que se encuentran obligatoriamente en todas las formaciones urbanas, si funciones que se manifiestan en cada uno de los tipos de formación histórica específica. Aunque la plaza, el mercado, el templo y otros sean funciones recurrentes en la literatura histórica de la ciudad, su mención se hace circunscrita a la

$15 C f$. Le Corbusier, A carta de Atenas (São Paulo: Hucitec/Edusp, 1993). 
caracterización de cada una de las formaciones históricas ya existentes ${ }^{16}$.

Es justamente por partieron de puntos distintos que arquitectos, historiadores o mismo sociólogos ven la ciudad teóricamente como cosa distinta. Para los primeros, la ciudad - o, al menos la ciudad de suya utopía colectiva - es un proyecto racional que se puede materializar antes o arriba de la historia y hasta del hombre. Para los segundos, ella es el registro temporal de la vivencia humana en un determinado sitio, luego, un hecho histórico per se. Ya para los terceros, la ciudad es el sitio donde las relaciones sociales ocurren, a saber, el palco para el representar cotidiano de los actores sociales, por tanto, un hecho social.

Pero si la distinción de puntos de partida y llegada es funcional para los más diversos conocimientos especializados sobre la ciudad y el urbano - y también para la legitimación de cada disciplina científica frente a las otras ${ }^{17}$ - son los esfuerzos "inter" o "transdisciplinarios" los que más contribuyen para hacer comunicar esferas discursivas que, en virtud de la especialización decurrente de la alta racionalización asumida por las ciencias, muchas veces ni siquiera se comunican. Esa carencia de comunicación entre los conocimientos que constituyen aquello que llamamos de campo de estudio del urbano ${ }^{18}$, a pesar de ser el resultado de la alta especialización científica - es decir, de aquello tipo de abordaje que torna posible conocer el objeto a fundo en sus detalles -, resulta, como paradoja, en un comprometimiento de las posibilidades de percepción

$16 C f$. Jean Lebrun apud Jacques Le Goff, Por amor às cidades (São Paulo, Brasil: Editora Unesp, 1998), 9-10.

17 Cf. Silva.

18 Hablamos acá de un campo de estudio del urbano como una zona de diálogo y confluencia de las diversas racionalidades, las diversas voces, los diversos aportes, las diversas miradas, los diversos conocimientos que desde tiempos remotos se dedican a desvendar, interpretar, representar y construir intelectualmente, imaginariamente o simbólicamente la ciudad y el urbano. Así, nuestra propuesta es más alargada que aquella presentada por Mark Gottdiener cuando habla de una ciencia urbana, una vez que ello se limita al campo científico mientras nuestra propuesta abarca otros conocimientos a ejemplo del arte. $C f$. Mark Gottdiener, A produção social do espaço urbano (São Paulo: Edusp, 1993). 
más amplias del propio objeto, a saber, la ciudad y el urbano. La cita abajo refuerza nuestra posición:

La ciudad, lejos de ser el objeto reducido que la ciencia positiva inventó para facilitar suya apropiación conceptual y sus esfuerzos analíticos, es un fenómeno socio-espacial plural, incierto, dinámico y dialéctico, que necesita de una mirada que sea capaz de captar, comprender y explicar su complejidad. La reducción teórico-metodológica de los objetos complejos para los objetivos de la análisis positiva, se no viene acompañada de un esfuerzo de re-totalización de su complejidad - cuya tarea sea hacer evidentes los limites de suya propia fragmentación - curre el riesgo de producir verdaderas mutilaciones en el objeto, conformando o, al menos, influenciando [...] no solamente el imaginario científico pero igualmente el imaginario social a respecto del objeto mutilado ${ }^{19}$.

El diálogo de la ciencia con el arte, específicamente la Literatura, en el campo de estudio de la ciudad y del urbano como aquí proponemos, es, de un lado, una forma de ampliar los medios por los cuales se intenta captar lo real para conocerlo y explicarlo, y de otro, una de las muchas maneras de, sin despreciar el valor intrínseco de las conquistas disciplinares de las ciencias sociales y humanas, ayudar a encerar de una vez el debate premoderno, ya anacrónico, sobre la legitimidad de esas ciencias y la validad de sus métodos y conquistas. Como afirman Martins, Eckert y Novaes:

Preciosos textos de clásicos de las ciencias sociales quedaron longo tiempo a la margen del legitimo y del aceptable, simplemente porque innovaban en la metodología y proponían una ciencia que fuese al mismo tiempo compatible con las singularidades

$19 C f$. Silva, 184 - traducción nuestra. 
vivas de su objeto ${ }^{20}$.

Vale decir, sin embargo, que eso no es un movimiento de apartamiento natural entre el pensamiento científico y el pensamiento literario, tampoco un movimiento circunscrito a las ciencias sociales, pero una tendencia que se va desarrollando desde el siglo XVII, cuando la especialización de las disciplinas científicas en todas las áreas empieza a ganar fuerza paralelamente a la lógica de la extrema racionalización científica, hasta la segunda mitad del siglo XX, cuando la tradicional relación de apartamiento entre ciencia y literatura (arte) sufre una importante inflexión en virtud de cambios relevantes en la lógica racionalista dominante hasta entonces en la ciencia, la cual pasa a reconocer y incorporar el imaginario, además de admitir el alcance filosófico y metafísico de suyas conclusiones ${ }^{21}$.

Como discutido arriba, el estudio de la ciudad y del urbano también sufre los efectos históricos de la racionalización y de la especialización disciplinaria. De modo que la ciudad fragmentase en muchas partículas explicativas poco o nada comunicables, las cuales, cada una a su manera, la reducen a algo que ella solo es en parte. Se nos inclinamos sobre el fenómeno de la ciudad sin los filtros previos de la lógica segregacionista y racionalista de la ciencia tradicional, percibimos luego que aquello a que llamamos ciudad no cabe perfectamente en ninguna de las cajitas en las cuales la ponen las diversas disciplinas que la estudian. Es preciso, por tanto, hacer comunicar las cajas donde reposan los pedazos de esa ciudad descuartizada, de modo que podamos al menos saber que aquellos fragmentos al cuales conocemos en detalles son partes de ella, pero no ella propiamente.

$20 \quad C f$. José de Souza Martins, Cornelia Eckert y Sylvia Caiuby Novaes, O imaginário e o poético nas Ciências Sociais (Bauru: Edusc, 2005), 7 - traducción nuestra.

$21 C f$. Simone Vierne, "Ligações tempestuosas: a ciência e a literatura", en A ciência e o imaginário (Brasília: Edunb, 1994). 
Como dicen Martins, Eckert y Novaes, "el humano se da a mirar de muchos modos"22. Y nuestra perspectiva acá es la de que la ciudad, arriba de todo, es un hecho humano, luego, pide más que las más profundas explicaciones de la ciencia tradicional, mucho atenta a los hechos exteriores - materiales - pero poco interesada en la dimensión inmaterial de sus objetos. La Literatura, obra de la combinación de la razón con el imaginario, del real con la creación, del particular con el colectivo, del pasado con el presente y el futuro, es un recurso rico, porque plural y libre, para la mirada de eso hecho humano. Suya incorporación al campo de estudio del urbano reflecte los avances de una ciencia que, ya segura de su estatuto, puede caminar rumo a un tratamiento más amplio y plural de sus objetos, reconociendo en ellos su complejidad inherente.

\section{Ciudad, imaginario, Literatura y Historia}

Es por medio de la ruptura con los paradigmas clásicos de comprensión de la vida y de las formas de aprensión del real que Gaston Bachelard nos enseña, en su obra sobre la filosofía de la materia ${ }^{23}$, a pensar la dimensión imaginaria que abarca cualquiera construcción sobre lo que se acostumbró a llamar de real.

Se puede percibir el imaginario como dimensión del real en muchos ejemplos de la Literatura. Un de ellos es el dialogo entre Marco Polo y Kublai Khan presente en el libro As cidades invisivei ${ }^{24}$ ("Las ciudades invisibles"), de Ítalo Calvino. Cuando Kublai Khan pide a el narrador para que hables de su ciudad, Marco Polo le responde que lo tiempo todo hablaba de

22 Martins, Eckert y Novaes, 9 - traducción nuestra.

$23 C f$. Gaston Bachelard, A poética do espaço (São Paulo: Editora Martins Fontes, 2000).

Gaston Bachelard, A poética do devaneio (São Paulo: Martins Fontes, 1988).

24 Ítalo Calvino, As cidades invisiveis (São Paulo: Companhia das Letras, 1990). 
Venecia cuando describía las ciudades que había visitado, porque aquella era la única imagen que le transmitía el sentido de ciudad ${ }^{25}$.

Otro ejemplo, también del obra de Ítalo Calvino, ahora en el libro $O$ caminho de San Giovanni $^{26}$ ("El camino de San Giovanni”), es la descripción sobre la tarea domestica de poner "la basura fuera". El autor construye un diálogo con los recuerdos que esa tarea le traía respecto de la ciudad de su infancia y también del Paris moderno, donde entonces vivía. En ese libro, la ciudad es siempre mirada y retratada por el ángulo de las experiencias personales de Calvino. Es como si solamente elle la tuviese desfrutado y comprendido su sentido. Otras personas también pusieron su basura en las calles de Paris, pero, de cierto, en virtud de la subjetividad y del imaginario, describirían ese acto de otras maneras caso lo quisiesen describir ${ }^{27}$.

Eses y otros ejemplos sacados de la Literatura nos dan la certeza de que para la nueva ciencia social - nueva en oposición a las vertientes científicas más tradicionales y racionales cualquier forma de producción del conocimiento es valida cuando se quiere profundizarse en la comprensión del caleidoscopio complejo que es la vida social, en particular la vida urbana.

Como dijimos, la ciudad - descuartizada por el racionalismo disciplinario de la ciencia clásica - no es solamente el espacio urbano y su apariencia. Ella es un hecho social, por tanto, también un conjunto inmaterial producido por y productor de los hombres en sociedad. Así, quien ambicionar captar la ciudad en su esencia tiene que mirarla a partir de un punto de vista interior y no como un viajero eventual o un turista sin compromiso con su sentido ontológico.

Los discursos de la pretensa objetividad científica, los llamados "estudios neutros", caen por tierra cuando se admite que las escojas y acciones humanas son guiadas también por la 25 Tânia Elias Magno da Silva, "Planejamento Urbano e os problemas ambientais ou a cidade das flores em jardins de cogumelos", Candeeiro - Revista de Política e Cultura da Secção Sindical dos Docentes da UFS (Brasil) 5 n.7-8 (2002): 25-31.

26 Ítalo Calvino, O caminho de San Giovanni (São Paulo: Companhia das Letras, 2000).

27 Tânia Elias Magno da Silva. 
subjetividad y no solamente por el cálculo racional, como pretenden los pensadores racionalistas. Las referencias o representaciones que el citadino produce respecto de su ciudad - la ciudad de la cual ello es componente orgánico y la cual le conforma socialmente - son resultados directos, aunque no exclusivos, de su subjetividad, sus sentimientos y suyas experiencias personales ${ }^{28}$.

Para la Historia, en particular, esas representaciones, verdaderas traducciones del real, son importantes porque orientan la manera como el hombre percibe y actua sobre ello ${ }^{29}$. Aceptar la dimensión imaginaria de la ciudad - y sus conexiones con la acción humana - es, de un lado, conceder al citadino un espacio de autonomía sobre la dominancia de los destinos históricos coercitivos y, de otro, reconocer la fragilidad de la pretensión teleológica en los estudios históricos, una vez que el hombre, en cierta medida, es también sujeto y no apenas objeto de la historia investigada.

\section{América Central: Ciudad, urbano y Literatura}

Situada en un contexto socio-histórico donde dialogan en un equilibrio poco estable el tradicional y el moderno, bien como entre el moderno y el postmoderno, la mayor parte de los países de la región centroamericana - sin pretender la sugerencia de una homogeneidad social para ellos - puede ser, grosso modo, caracterizada, del punto de mirada de los aspectos urbanos, por suya macrocefalia: la ciudad principal, siempre la capital nacional, posee peso demográfico, político, económico y social mucho mayor que las demás ciudades o aglomeraciones urbanas del país. La tabla 01 presenta datos que, aunque con diez años de distancia, apuntan para el

$28 \quad$ Ibid.

29 Serge Moscovici, La psychanalyse son image et son public (Paris: Presses Universitaires des France, 1961). 
fenómeno de la macrocefalia urbana en Centroamérica.

Paralelamente a la macrocefalia, las estadísticas apuntan como característica urbana de los países centroamericanos la urbanización más generalizada fuera de los círculos metropolitanos centrales. Sin embargo, la consideración a esa llamada urbanización general, del punto de vista demográfico al menos, pide, como indican Jordan y Simioni ${ }^{30}$, una reflexión más alongada sobre el concepto de urbanización utilizado en el principal instrumento de encuesta demográfica, el censo nacional. Los censos latinoamericanos - no apenas los centroamericanos - tienden a considerar urbanos sitios que demográficamente siquiera podrían ser así tratados. El caso brasileño es ejemplar. En Brasil, el censo computa como "ciudades" todas las sedes municipales, mismo que una tenga solamente dieciocho habitantes ${ }^{31}$. Ese criterio crea, evidentemente, una proyección del urbano para allá de suyas reales dimensiones y, junto a eso, la retórica de la superurbanización de la América Latina.

La urbanización, es decir, la concentración de población en sitios más aglomerados, es una tendencia mundial contemporánea. La América Central no huye a esa tendencia, pero presenta, aún, niveles medianos o hasta bajos de concentración poblacional urbana fuera de los sistemas urbanos "primados". Como apunta la tabla 02, mientras en el año 2000 solamente Costa Rica y Panamá (datos disponibles) presentaban más de 50\% de sus respectivas poblaciones habitando localidades "urbanas" - es decir, con más de 2 mil habitantes -, las proyecciones dicen que en el año 2010 - luego, diez años adelante - la mitad de los países centroamericanos - exceptuado Belice, por ausencia de datos - aún presentará tasa de urbanización inferior a $60 \%$ y ningún país tendrá tasa superior a 70\%. Para los parámetros de urbanización de la América Latina, se puede

$30 \quad$ Ibid., 36 - traducción nuestra.

31 Ese es el caso de la sede del municipio de "União da Serra" en el censo brasileño de 2000. Cf. José Eli da Veiga, Cidades imaginárias: o Brasil é menos urbano do que se calcula (Campinas: Autores Associados, 2002). 
llamar de mediana (y macro encefálica) la urbanización centroamericana.

Pero decir que la América Central se caracteriza por una urbanización mediana de tipo macro encefálico es solamente un de muchos pasos para le fotografiar el urbano en su complejidad. ¿Cuáles son las diversas fisionomías del urbano producidas ayer y hoy por esa urbanización concentrada y diluida? ¿Dónde se encuentran los trazos más y menos modernos del urbano en ese tejido poroso aquí y denso allá? Como se presenta el hombre urbano centroamericano en el tiempo? ¿Cuáles las marcas del urbano que se pueden sentir fuera de las grandes ciudades? ¿Cómo se constituyen las mentalidades en el contexto propio de la urbanidad centroamericana?

Hay muchas preguntas a las cuales los números de la demografía no pueden y tampoco pretenden responder. Para ayudar a hacerlas y a responderlas se presentan otras disciplinas científicas y también - esta es nuestra propuesta - la Literatura. Incluso con obras no dedicadas directamente a temas o enredos centroamericanos, la Literatura puede ser muy útil a los pesquisidores de la ciudad y del urbano, por presentar interpretaciones del real o creaciones a partir de ello que acá o allá se aproximan del real que se busca conocer por medio de la ciencia. La Literatura mundial se encuentra llena de ejemplos de obras que pueden servir al campo de estudio del urbano como auxiliares en las reflexiones iniciales, o mismo más avanzadas, del pesquisidor. Se trata, como discutido arriba, de un movimiento de alargamiento de las fronteras intelectuales de las diversas disciplinas dedicadas al estudio del urbano, con la aceptación y la incorporación de la dimensión imaginaria del objeto y de la propia ciencia.

Para eso, sin embargo, como apunta Peter Burke ${ }^{32}$, es necesario que la propia ciencia tenga pretensiones de abertura y no de clausura. Sus palabras, a respecto de la Historia, sirven a otras disciplinas que quieran dialogar con el saber artístico:

32 Peter Burke, "Pintores como historiadores na Europa do século 19", en $O$ imaginário e o poético nas Ciências Sociais, ed. José de Souza Martins, Cornelia Eckert y Sylvia Caiuby Novaes (Bauru: Edusc, 2005). 
Actualmente, la escritura de lo que se podría considerar historia "legítima" dejó de ser monopolio de historiadores profesionales [...]. Hoy somos más pluralistas y dejamos de lado la idea de "Historia" en el singular, con letra mayúscula, en beneficio de historias múltiplas. Una de las consecuencias de este cambio es la re-valuación de la historia no profesional en el pasado, incluyendo las obras de romancistas históricos, dramaturgos, compositores de óperas $-\mathrm{y}$ pintores ${ }^{33}$.

Incluso cuando el arte no se preste a ser una fuente más sensible de datos o hechos ${ }^{34} \mathrm{o}$ no promueva la traducción del intrincado discurso científico para una lenguaje más aceptable a los inexpertos ${ }^{35}$, creemos que ella puede figurar como una fuente de inspiración, es decir, un refugio para la creatividad sin la cual el pensamiento científico paralizase ante su monumental racionalidad. Suya ayuda es fundamental para la extensión de la mirada del cientista, independientemente de la disciplina a cual ello se encuentre afiliado.

Cuando Thomas Mann, en 1912, escribió su famosa novela Muerte en Venecia ${ }^{36}$, no hablada ello de los actuales balnearios turísticos caribeños, tampoco pretendía producir cualquiera explicación para los cambios culturales sufridos por las poblaciones de esos balnearios ante la convivencia con turistas de todas las partes del mundo. Ello simplemente contaba la historia de un artista y la tragedia de su encanto por lo bello. Pero el escenario escogido por el autor, un hotel de paseo en una isla del mar Adriático, que representaba el "exótico" para su personaje, estimula el pensamiento del cientista social y humano - sociólogo, historiador, antropólogo - a hacer una

$33 \quad$ Ibid., 15 - traducción nuestra.

34 Ibid.

$35 \quad C f$. Simone Vierne.

36 Cf. Thomas Mann, Morte em Veneza \& Tonio Kroger (Rio de Janeiro: Nova Fronteira, 2000). 
puente entre aquello contexto europeo del año "19..." ${ }^{37}$ y el contexto particular de las villas o ciudades de veraneo actuales, sean ellas situadas en las islas adriáticas o en las playas caribeñas. Unas como otras son zonas de confluencia del turista, un tipo de hombre muy particular y hoy en día también mucho generalizado, que lleva el urbano a los cantos más lejos del planeta, pero lleva un urbano suyo, un urbano extranjero.

El mismo se puede decir, por ejemplo, del romance de Miguel Sousa Tavares, Ecuador ${ }^{38}$. El autor narra la trayectoria de un joven político portugués enviado por el rey para administrar la colonia de San Tomé y Príncipe, en África, y su enlace con la mujer del representante diplomático del Reino Unido en la misma colonia, un casal venido de India. Nada habla Tavares de la América Central, pero su obra es demasiado inspiradora para aquellos que pretenden estudiar las relaciones políticas en contextos coloniales, bien como las relaciones sociales en rededor del poder. Así, un romance situado en dos pequeñas islas africanas, en las cuales la ciudad no es más de que una proyección extranjera del colonizador, puede ayudar a clarear la mirada de los historiadores y sociólogos en el estudio de las dimensiones políticas y sociales del pasado urbano colonial.

Esos son solamente dos mínimos ejemplos de cómo el arte, y sobretodo la Literatura, puede servir a los estudios del urbano en América Central, mismo que la producción literaria no sea local y tampoco se dirija a creaciones ubicadas en el continente o mismo en la ciudad.

Poseyendo características de urbanización tan expresivas en sus particularidades y generalidades, que van desde la metrópolis moderna latinoamericana - densa, violenta, sucia, segregacionista, llena de pobres y desempleados -, hasta pequeños centros del turismo internacional - verdaderos paraísos de exotismo y naturaleza para disfrute de extranjeros ricos -, la América Central, tierra de pasado colonial y presente aún dependiente, solo tiene a ganar con

$37 \quad$ Ibid., 3.

38 Miguel Sousa Tavares, Ecuador (Rio de Janeiro: Nova Fronteira, 2004). 
el diálogo entre la ciencia y el arte en el estudio de la ciudad y del urbano.

\section{Consideraciones conclusivas}

Concluimos nuestras reflexiones retomando el punto del cual partimos: la ciudad, objeto complejo de investigación científica, constituye un campo de estudio privilegiado para la interdisciplinaridad y también para el alargamiento de las fronteras intelectuales de la ciencia como un todo. La Literatura, por la libertad creativa y el componente imaginario que la caracterizan, es un canal válido y rico para las finalidades investigativas del campo de estudio del urbano, sendo útil no solamente como fuente de datos o medio explicativo del discurso científico, pero, también, como estímulo a la inspiración y la imaginación indispensables a la buena producción de la ciencia. Esas conclusiones generales, porque teóricas, sirven empíricamente para orientar los estudios socio-espaciales presentes o pasados - sociológicos, arquitectónicos, históricos y otros - en cualquier contexto urbano, ahí incluso el centroamericano, con suyas particularidades y generalidades. 
Indexaciones: Repositorio de Revistas UCR, DIALNET, Latindex, REDALYC Directorio y recolector de recursos digitales del Ministerio de Cultura de España, Directory of Open Access Journals.

Diálogos Revista Electrónica de Historia ISSN 1409-469X. Número especial 2008. Dirección web: http://historia.fcs.ucr.ac.cr/dialogos.htm

\section{Tablas}

Tabla 01 - América Central - Porcentaje de población en el área urbana principal, 2000 y índice de primacía, 1990

\begin{tabular}{|l|l|c|c|}
\hline \multirow{2}{*}{ País } & \multicolumn{3}{|c|}{ Área metropolitana principal } \\
\cline { 2 - 4 } & Nombre & Porcentual de población* & Índice de primacía $^{1 * *}$ \\
\hline Belice & Ciudad Belice & 21.2 & -- \\
\hline Costa Rica & San José & 23.9 & -- \\
\hline El Salvador & San Salvador & 21.6 & -- \\
\hline Guatemala & Ciudad de Guatemala & 28.8 & 9.6 \\
\hline Honduras & Tegucigalpa & 14.9 & 1.6 \\
\hline Nicaragua & Managua & 20.0 & 2.8 \\
\hline Panamá & Ciudad de Panamá & 41.5 & 3.9 \\
\hline
\end{tabular}

*Fuente: CEPAL. Anuario estadístico de América Latina y el Caribe, 2007, http://www.cepal.org/cgi-bin/getProd. asp? xml=/publicaciones/xml/8/32598/P32598.xml\&xsl=/deype/tpl/p9f.xsl\&base=/tpl/top-bottom.xsl, $\quad$ pesquisado en $27 / 04 / 2008$.

**Fuente: Ricardo Jordan y Daniela Simioni, Ciudades intermedias de América Latina y el Caribe: propuestas para la gestión urbana (CEPAL y Ministero degli Affari Esteri Cooperazione Italiana, 1998), 42. 
Tabla 02 - América Central - Estimativa de la tasa de urbanización para el año de 2010 y porcentaje de población que residen en localidades de 2 mil y más habitantes (2000)

\begin{tabular}{|c|c|c|}
\hline País & Tasa de urbanización (2010)* & $\begin{array}{c}\text { Porcentaje de población en localidades a parir } \\
\text { de } 2 \text { mil habitantes }(2000)^{* *}\end{array}$ \\
\hline Costa Rica & 66,0 & 54,2 \\
\hline El Salvador & 60,3 & -- \\
\hline Guatemala & 57,2 & 47,7 \\
\hline Honduras & 50,6 & 43,9 \\
\hline Nicaragua & 58,2 & -- \\
\hline Panamá & 68,7 & 61,6 \\
\hline
\end{tabular}

*Fuente: CEPAL. América Latina: proyecciones de población urbana y rural (1970-2025). Boletín demográfico 76, julio 2005.

**Fuente: CEPAL. América Latina: Urbanización y Evolución de la Población Urbana, 1950-2000. Boletín Demográfico 75, enero 2005, p. 30. Base de datos DEPAULC, 2004. Boletín Demográfico Nos. 56 y 63.

(Footnotes)

1 “Tradicionalmente calculado como el cociente entre la población de la ciudad principal y la suma de las poblaciones de las tres ciudades que le siguen en tamaño". $C f$. Ricardo Jordan y Daniela Simioni, Ciudades intermedias de América Latina y el Caribe: propuestas para la gestión urbana (CEPAL y Ministero degli Affari Esteri Cooperazione Italiana, 1998), 37. El índice de primacía superior a 2.0 ya indica tendencia macro encefálica. 